\title{
É possível o "domínio dos afetos" no trabalho docente? Considerações a partir de Espinosa e Marx
}

\section{Resumo}

Este ensaio debate os conceitos de afeto e vontade no trabalho docente e seus vínculos com o "voluntarismo pedagógico" presente em diversas concepções e políticas sobre a educação de crianças. Utiliza-se da doutrina espinosana dos afetos e também da noção de trabalho estranhado nos Manuscritos EconômicoFilosóficos de Marx para uma meditação sobre o perfil sociológico dos professores da educação básica (e pública) brasileira. Suas considerações finais ressaltam a importância de Espinosa na crítica do "domínio absoluto dos afetos" e análise das atuais condições nas quais se realiza o trabalho docente, apresentando pontos de convergência - e uma possível divergência - com relação a ideias de Mészáros na busca de uma educação "para além do capital”. Palavras-chave: domínio dos afetos, trabalho alienado, Spinoza.

\begin{abstract}
This paper discusses affect and will in educational work and their connections with the "pedagogical voluntarism" presented in conceptions and policies for children's education in Brazil. It employs Spinoza's doctrine of affects and also the concept of alienated work in Marx's Economic and Philosophic Manuscripts of 1844 to writing about the sociological profile of Brazil's childhood teachers. Its final remarks emphasize the importance of Spinoza's critique of "absolute mastery of affects" and of current work conditions in which teaching takes place, presenting points of similarity - and one possible difference - with the Mészáros's search for an education "beyond capital".
\end{abstract}

Keywords: mastery of affects, alienated work, Spinoza. 
Os que escreveram sobre os afetos e o modo de vida dos homens parecem, em sua maioria, ter tratado não de coisas naturais, que seguem as leis comuns da natureza, mas de coisas que estão fora dela. Ou melhor, parecem conceber o homem na natureza como um império num império. Pois acreditam que, em vez de seguir a ordem da natureza, o homem a perturba, que ele tem uma potência absoluta sobre suas próprias ações, e que não é determinado por nada mais além de si próprio. (Ét. III. Prefácio. p.161)

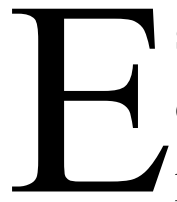

ste ensaio tece considerações sobre afetos e vontade no trabalho docente e seus vínculos com o "voluntarismo pedagógico" presente em diversas concepções e políticas sobre a educação de crianças. Para isso, relaciona conceitos básicos da doutrina espinosana dos afetos com o trabalho docente a partir dos Manuscritos EconômicoFilosóficos de Marx, realizando uma interpretação psicofísica da caracterização sociológica do perfil dos trabalhadores da educação brasileira (por Gatti e Barreto, 2009).

Destinado aos espinosanos pouco familiarizados com o marxismo, e aos marxistas pouco familiarizados com o espinosismo, este ensaio afirmase como introdutório e não poderá recorrer a uma análise diacrônica dos conceitos, nem consulta aos textos em seus idiomas originais. Sem pretender construir analogias que acabem por servir ambas as tradições na sopa do ecletismo; remetendo o(a) leitor(a) à exposição de alguns dos difíceis problemas nas ideias políticas de Marx e Espinosa (Chaui, 1983), a autora deste texto procura o diálogo entre as tradições, sem pretensão de uma síntese. Adota-se como pressuposto mediador de tal diálogo a seguinte tese do psicólogo marxista Lev Semionovich Vygotski (1896-1934): a obra espinosana poderia ser referência para um modelo de natureza humana, para a própria formação de uma ideia de homem (2004, p.59) pelo marxismo ${ }^{1}$. Nesse campo discursivo, Vigotski elegeu o problema psicofísico, ou seja, o estudo da relação mente-corpo, como seu principal foco de interesse na

1 Credita-se tal ideário à presença de Espinosa entre os marxistas soviéticos, particularmente Plekhanov e Deborin (veja-se Kline, 1952).

Filosofia e Educação - ISSN 1984-9605 - Volume 5, Número 1

Abril - Setembro de 2013 
doutrina espinosana dos afetos, contrapondo-se a Descartes e sua defesa da "vontade livre".

A ideia de "partida" em Espinosa e Marx é bastante importante, pois a presença de Chaui (intérprete da doutrina psicofísica e de diversos outros temas na exegese espinosana) e Mészáros (analista das perspectivas de uma educação para além do capital) renova a potência dos dois autores clássicos na interpretação do trabalho docente em nossa época.

A exposição organiza-se em quatro partes, a partir dos seguintes eixos temáticos:

I. Espinosa e os afetos como problema psicofísico: conceitos principais

II. Notas sobre a essência do trabalho estranhado

III. É possível o "domínio dos afetos" no trabalho docente?

IV. Considerações finais

\section{I}

No corolário à proposição 13 da parte II da Ética, ao comentar que o objeto de nossa mente é o corpo existente em ato, conclui Espinosa: "Segue-se disso que o homem consiste de uma mente e de um corpo, e que o corpo humano existe tal como o sentimos." (2008, p.97) O corpo é maneira definida e determinada do atributo extensão; a mente, do atributo pensamento. As ideias, a vontade, os afetos (enquanto ideias das afecções do corpo) são todos compreendidos no pensamento. Não há diferença de substância entre ideia e coisa: um círculo existente na natureza e a ideia desse círculo são uma só e a mesma coisa. Um modo da extensão e a ideia dele são uma só e a mesma coisa, expressando-se de duas maneiras ${ }^{2}$.

\footnotetext{
2 "como demonstra Espinosa, o homem é uma parte da Natureza e exprime de maneira certa e determinada a essência e a potência dos atributos substanciais. De maneira certa: um ser humano é uma singularidade que possui uma forma singular e não outra e nenhuma outra. De maneira determinada: a forma singular de um ser humano é produzida pela ação causal necessária da Natureza Naturante (os atributos substanciais) e pelas operações necessárias das leis da Natureza Naturada (o mundo)" (Chaui, 2011, p.146).
}

Filosofia e Educação - ISSN 1984-9605 - Volume 5, Número 1

Abril - Setembro de 2013 
“A ordem e a conexão das ideias é o mesmo que a ordem e a conexão das coisas" (Espinosa, 2008, p.87). Por isso, tudo que ocorre no corpo é percebido pela mente (embora não seja, necessariamente, rotulado por ela). O corpo humano, para Espinosa, é um todo composto. A sequência explicativa da proposição 13, na parte II da Ética, evidencia os processos físico-fisiológicos próprios aos corpos e completa-se com as considerações de que o corpo humano é ser composto de muitos indivíduos, os quais, por sua vez, compõem-se de corpos mais simples. O indivíduo consiste, pois, em ente coletivo: "é composto de um grande número de indivíduos de natureza diferente, e pode, portanto, ser afetado de muitas e diferentes maneiras por um só e mesmo corpo" (2008, p.185). Nele existem partes duras, moles e fluidas, em movimento e repouso, havendo uma transmissão interna de forças e mudanças de forma. "De acordo com Espinosa, definidos pelo conatus como potentia agendi, ou potência de agir, os indivíduos se definem pela variação incessante de suas proporções internas de movimento e repouso" (Chaui, 2011, p.48). Nesse campo semântico, Chaui atribui ao corpo a condição de ente singular dinâmico, sistema complexo de movimentos internos e externos, cuja intercorporeidade emana de dois aspectos: "de um lado, porque ele é, enquanto um ser singular, uma união de corpos; de outro, porque sua vida se realiza na coexistência com outros corpos externos" (idem, p.73).

Certo indivíduo composto pode ser, então, afetado de muitas maneiras e ainda conservar sua natureza. Espinosa afirma: os indivíduos que compõem o corpo humano, e, por conseguinte, ele próprio, são afetados pelos corpos exteriores de muitas formas. Por sua vez, também afetam (modificam, alteram) os corpos exteriores, sendo, desses processos, causa adequada ou inadequada.

$\mathrm{Na}$ concepção "psicofísica" de Espinosa, a capacidade de afetar é indissociável da de ser afetado, bem como da natureza dos corpos que se afetam. Isso se acompanha da existência de ideias na mente acerca do 
próprio corpo e dos demais. Mas - ponto fundamental na causalidade das nossas ideias - elas indicam mais o estado de nosso corpo enquanto afetado pelos exteriores que a natureza de qualquer deles (Espinosa, 2008, p.107). Pois, em primeiro lugar, a mente é a ideia do seu corpo existente em ato: a ideia de uma afecção (mudança decorrente da relação com outro corpo) do corpo persiste enquanto este for afetado. E, posteriormente, a mente pode considerar presentes os corpos exteriores pelos quais o corpo humano, do qual constitui a ideia, foi antes afetado, conservando deles as ideias imaginativas enquanto durar a afecção correspondente.

Como propriedade de nossa imaginação ${ }^{3}$, podemos considerar presentes coisas que não existem. Esta é uma virtude da mente, sendo errônea apenas caso não se percebam razões para dúvida. As imaginações são forma adequada de conhecimento do estado do corpo em ato e inadequada de suas relações com outros corpos: são ideias confusas, conclusões sem premissas. Pela sua virtude a um só tempo cognoscente e confusa, é posta no primeiro gênero de conhecimento espinosano. Ao todo, esses gêneros são três: I. A imaginação (Chaui, 2005, pp.35-36); II. As noções comuns e as ideias adequadas das propriedades das coisas; III. A ciência intuitiva ${ }^{4}$.

A memória é certa concatenação de ideias que envolve a natureza das coisas exteriores segundo a ordem e a concatenação das afecções do

\footnotetext{
${ }^{3}$ Chaui $(2005$, p.32) afirma que, no século XVII, "imaginação" não significa fantasia criadora, mas sensação, percepção e memória. A imaginação é o conhecimento sensorial que produz imagens das coisas em nossos sentidos e cérebro. "Uma imaginação é uma ideia pela qual a mente considera uma coisa como presente" (Espinosa, 2008, p.277)

${ }^{4}$ No Escólio 2 da Proposição 40, Parte II: "De tudo o que foi anteriormente dito conclui-se claramente que percebemos muitas coisas e formamos noções universais: 1. A partir de coisas singulares, que os sentidos representam mutilada, confusamente, e sem a ordem própria do intelecto [...]. Por isso, passei a chamar essas percepções de conhecimento originado da experiência errática. 2. A partir de signos; por exemplo, por ter ouvido ou lido certas palavras, nós nos recordamos das coisas e delas formamos ideias semelhantes àquelas por meio das quais imaginamos as coisas [...]. Vou me referir posteriormente, a esses dois modos de considerar as coisas como conhecimento de primeiro gênero, opinião ou imaginação. 3. Por termos, finalmente, noções comuns e ideias adequadas das propriedades das coisas [...]. A este modo me referirei como razão e conhecimento de segundo gênero. Além desses dois gêneros de conhecimento, existe ainda um terceiro, como mostrarei a seguir, que chamaremos de ciência intuitiva" (Espinosa, 2008, p.135)
}

Filosofia e Educação - ISSN 1984-9605 - Volume 5, Número 1

Abril - Setembro de 2013 
corpo humano. Portanto, depende do hábito ou experiências pregressas de quem imagina. A variedade e dinâmica das afecções é obstáculo para a mente formar um conhecimento adequado das mesmas: ela não compreende as concordâncias, diferenças e oposições entre todas as coisas. Já as ideias adequadas revelam a potência da mente:

Escólio. Como não há nada de que não se siga algum efeito [...], e como compreendemos clara e distintamente [...] tudo o que se segue de uma ideia que é, em nós, adequada, segue-se que cada um tem o poder, se não absoluto, ao menos parcial, de compreender a si mesmo e de compreender os seus afetos, clara e distintamente e, consequentemente, de fazer com que padeça menos por sua causa. Devemos, pois, nos dedicar, sobretudo, à tarefa de conhecer, tanto quanto possível, clara e distintamente, cada afeto, para que a mente seja, assim, determinada, em virtude do afeto, a pensar aquelas coisas que percebe clara e distintamente e nas quais encontra a máxima satisfação (Espinosa, 2008, p.373).

A imaginação é, antes de tudo, processo corporal e passivo - forma de conhecimento inerente à condição humana, forma de conhecimento própria de nosso estado de natureza. Espinosa (2008, p.143-145) edifica, a partir da multiplicidade constitutiva da mente e do corpo, uma doutrina dos afetos que se caracteriza por uma recusa da faculdade de compreender, desejar ou amar como posse transcendente e abstrata do ser humano. A vontade não subordina o desejo. A vontade é o próprio desejo, enquanto referido à mente. É a determinação da mente a pensar, a afirmar ou negar alguma coisa. Pensamos falar ou calar por livre determinação da mente, mas nossas “decisões" não são mais do que os apetites, enquanto referidos à mente (idem, p.171).

Em um contexto de negação da potência absoluta da mente com relação ao corpo, Espinosa define: 
3. Por afeto compreendo as afecções do corpo, pelas quais sua potência de agir é aumentada ou diminuída, estimulada ou refreada, e, ao mesmo tempo, as ideias dessas afecções.

Explicação. Assim, quando podemos ser a causa adequada de alguma dessas afecções, por afeto compreendo, então, uma ação; em caso contrário, uma paixão. (Espinosa, 2008, p.163) .

As definições de ação e paixão mostram como o homem pode ser causa adequada de seus afetos, ou apenas se assujeitar à variação das causas externas, o que depende da qualidade de nossos desejos, e da maneira como nos relacionamos com as numerosas, e infinitamente mais poderosas, forças externas. Depende, ainda, da natureza do desejado, e do fato de o que se deseja ser ou não obtido (Chaui, 2005, p.60). Verificamos, assim, que nosso corpo e mente são sistemas de vivências afetivas (Chaui, 2011, p.92).

Agimos quando, em nós ou fora de nós, sucede um efeito de que somos causa adequada, passível de ser compreendida de forma clara e distinta a partir de nossa essência (Espinosa, 2008, p.163-165). Vale dizer que as paixões têm por fonte um conhecimento inadequado: meras opiniões que, como ondas, formam-se e dissipam-se com a próxima afecção. Pois, se tudo soubéssemos do que nos afeta, menos estaríamos sujeitos às paixões. $\mathrm{O}$ conceito de afeto como ação refere-se a uma mente mais capaz de pensar as causas reais das afecções, e a um corpo mais capaz de agir, sem o assujeitamento às causas voláteis que transitam pela experiência vaga. Esforçamo-nos para que o corpo de nossa infância transforme-se, tanto quanto lhe permitir sua natureza e conveniência, tornando-se capaz de muitas coisas, referido a uma mente com extrema consciência delas, de si, de deus (Espinosa, 2008, p.407). Quanto mais um corpo é capaz de agir/padecer simultaneamente sobre um número maior de coisas, mais o é a

${ }^{5}$ Essas transições de potência/realidade são a mudança do conatus, ou essência atual, ou desejo (enquanto referido ao corpo e à mente, como apetite consciente), ou vontade (enquanto referido apenas à mente), ou apetite (enquanto referido apenas ao corpo). É esclarecedor observar que nem todas as afecções implicam em uma mudança de potência, conforme se lê na parte III da Ética, Postulado 1 (idem, p.163).

Filosofia e Educação - ISSN 1984-9605 - Volume 5, Número 1

Abril - Setembro de 2013 
sua mente (p.231).

A vida em sociedade exerce papel especial em nossos afetos: as proposições 21 a 30 da parte III (Espinosa, 2008, p.189-199) são capitais na caracterização de sua natureza social e política, melhor desenvolvida nas duas últimas partes da Ética. Aí, Espinosa considera: aquilo que se assemelha a nós é, apenas por isso, causa dos afetos. Ora, nada se nos assemelha tanto quanto outras pessoas (e, além disso, há bens e males que só um ser humano pode proporcionar a outro: somos, pois, causa de desejo). Nossos próprios afetos variam diretamente com os que imaginamos afetar as pessoas amadas e se associam às presumidas causas desses afetos originais, pois a potência/impotência dos amados aumenta ou diminui a nossa. O mesmo para os afetos de outros seres que, sob algum aspecto, julgamos semelhantes a nós. Essa propriedade é a imitação dos afetos. Muito saliente na infância, dela "se segue que os homens são misericordiosos [...] também que eles são invejosos e ambiciosos" (Espinosa, 2008, p.201) ${ }^{6}$.

A parte III da Ética estrutura um modelo multicausal para os afetos humanos, cuja complexidade transcende os limites deste ensaio. A título de ilustração, destacamos alguns aspectos: o aumento da potência ao longo do desenvolvimento do indivíduo condiz com uma multiplicação das ações e pensamentos geradores de efeitos no mundo, principalmente por relações de contiguidade e semelhança. A intensidade dos afetos depende, também, de imaginarmos serem gerados por uma causa livre: assim, o mal supostamente infligido por uma pessoa causa-nos mais ódio que aquele envolvendo desastres naturais (Espinosa, 2008, p.217). O contexto, as circunstâncias, são também importantes: podemos ser levados a querer um mal menor (o temor), para evitar um maior. Dessa gênese e dinâmica decorrem novos desejos, ações e pensamentos: tenderemos a aliviar a desgraça de quem nos

\footnotetext{
${ }^{6}$ Como as imagens das coisas são afecções do corpo que envolvem a natureza de nosso corpo e a do corpo exterior: "se a natureza de um corpo exterior é semelhante à de nosso corpo, então a ideia do corpo exterior que imaginamos envolverá uma afecção de nosso corpo semelhante à do corpo exterior. [...] Essa imitação dos afetos, quando está referida à tristeza, chama-se comiseração" (Espinosa, 2008, p.195)
}

Filosofia e Educação - ISSN 1984-9605 - Volume 5, Número 1

Abril - Setembro de 2013 
causa misericórdia, a destruir quem odiamos, a devolver o mal a quem nos prejudicou, e a sermos gratos a quem nos ama sem que imaginemos um motivo para isso. Em termos de compreensão singular das paixões, Espinosa (idem, p.231-233) considera que o conhecimento da natureza de cada uma deve exprimir a natureza do objeto pelo qual somos afetados, bem como a do nosso desejo e a potência de ânimo reguladora dessa paixão.

\section{II}

Não é possível afirmarmos que haja em Marx extensa teorização sobre os afetos (sejam paixões, emoções, sentimentos ou outros vocábulos presentes em diversos idiomas modernos, conforme Engelmann, 1978). É justo afirmar, também, que raras - e algo reiterativas - são suas referências a Espinosa $^{7}$. O presente artigo não abordará essas relações, mas sim a concepção marxiana de trabalho como demiurgo da sociedade (presente desde os seus Manuscritos Econômico-Filosóficos, datados de 1844). Enquanto a Ética espinosana não objetiva uma exposição comparativa de diversas formações societais, dos Manuscritos em diante (segundo Gianotti, 1999) a análise marxiana da sociedade envolve sempre a crítica da economia política, a partir de uma análise histórica (aspecto metodológico pelo qual se aproximaria mais do Tratado Teológico-Político que da Ética). Os Manuscritos são particularmente ricos na exposição do dilaceramento do trabalho pela produção capitalista, por meio da figura do trabalho estranhado. Aí expõe-se a desumanização espiritual e corporal: com "imoralidade, deformação, embrutecimento de trabalhadores e capitalistas" (p.93). Mesmo Adam Smith e Jean-Baptiste Say admitiam que o interesse do trabalhador não se contrapunha ao da sociedade, mas a sociedade sempre e necessariamente a ele se contrapunha (Marx, 2010, p.29). Posteriormente estabelecida pelo autor como contradição fundadora da história, a luta de

${ }^{7}$ Conforme Chaui (1983) e Hull (2000).

Filosofia e Educação - ISSN 1984-9605 - Volume 5, Número 1

Abril - Setembro de 2013 
classes torna-se indigesta determinação - ou, metaforicamente falando: um ovo de serpente - na gênese dos afetos, como veremos a seguir.

Marx elabora sua própria concepção de trabalho negando o quadro idealista no qual Hegel o havia disposto ${ }^{8}$, ao diferenciar - conforme Ranieri (2010) - alienação (Entäusserung) e estranhamento (Entfremdung). O trabalho estranhado determina o engendrar-se do ser social:

O meio pelo qual o estranhamento procede é [ele] mesmo um [meio] prático. Através do trabalho estranhado o homem engendra, portanto, não apenas sua relação com o objeto e o ato de produção enquanto homens que lhe são estranhos e inimigos; ele engendra também a relação na qual outros homens estão para a sua produção e o seu produto, e a relação na qual ele está para com estes outros homens (Marx, 2010, p.87).

O trabalhador relaciona-se com o seu trabalho de modo não-livre. A opressão humana envolve-se na relação do trabalhador com a produção, sendo as relações de servidão, fundamentalmente, modificações e consequências desse estranhamento original, que viola também o processo de trabalho e reapropriação do trabalho exteriorizado, nos seus aspectos genéricos. Voga o princípio marxiano de que a natureza é o corpo do homem, necessário para ele evitar a morte. O fato de que a vida física e mental interconecta-se com a natureza, "não tem outro sentido senão que a natureza está interconectada consigo mesma, pois o homem é uma parte da natureza" (idem, p.84). Mas ele se relaciona com o gênero como com sua própria essência; relaciona-se consigo mesmo como ser genérico. E é somente porque há universalidade em seu trabalho - diferentemente das

\footnotetext{
${ }^{8}$ Segundo Lukács (2009) em análises econômicas anteriores aos Manuscritos, Marx "distinguiu nitidamente entre a objetivação no trabalho como tal e a alienação humana que se manifesta na forma especificamente capitalista do trabalho. Portanto, foi a crítica da economia capitalista, na perspectiva da abolição da alienação, que fez com que Marx fosse capaz de superar o quadro idealista no qual Hegel abordou e resolveu incorretamente o problema da alienação.” (p.188-189)
}

Filosofia e Educação - ISSN 1984-9605 - Volume 5, Número 1

Abril - Setembro de 2013 
atividades vitais de outros animais - que ele pode suprir não suas necessidades, mas sim as de outrem.

Dupla miséria, a do trabalhador! Além de realizar trabalho forçado, ser expropriado do pôr teleológico que caracteriza sua atividade vital, também perde essa conexão elementar entre as necessidades e os produtos que se destinariam a saciá-las. O que permanece para ele? O salário, na forma dinheiro, sendo marcante a segmentação e a produção de abstrações no decorrer de toda a atividade, que simboliza não mais a efetivação da vida física e mental do homem em sua ação sobre a natureza (aí inclusa sua própria natureza), mas sim a perda da vida, pois ela ficou no objeto: quão maior a atividade, mais sem-objeto é o trabalhador (Marx, 2010, p.84). E a relação com outros homens - fundamental para sua existência objetiva e efetiva (idem, p.87) - converte-se em uma relação entre desconfiados concorrentes. O dinheiro torna-se objeto de desejo universal como potencial mediador da aquisição das mercadorias nas quais o trabalho se dilacerou, lembrando-nos Espinosa e sua observação de que o dinheiro passa a ocupar inteiramente a mente do vulgo: passaporte para as muitas coisas necessárias a nutrir o corpo e possibilitar o trabalho da mente ${ }^{9}$. Na essência do trabalho estranhado vigora a condição dos homens como pacientes e não agentes; servis e não livres, engalfinhando-se em uma constante disputa por bens finitos. Dela, decorre o fato de que os homens, ao invés de terem a colaboração racional no centro da vida social, odeiem-se e obstaculizem-se mutuamente.

Desdobramento lógico dessas ideias sobre o trabalho estranhado é a noção marxiana de que a efetiva emancipação humana universal (a emancipação com relação à exploração do homem pelo homem) demanda a

\footnotetext{
${ }^{9}$ Tratando das coisas necessárias para nutrir o corpo, afirma Espinosa: "Capítulo 28. Entretanto, para obter essas coisas, dificilmente bastariam as forças de cada um, se os homens não prestassem serviço uns aos outros. $\mathrm{O}$ fato é que todas as coisas acabaram por se resumir ao dinheiro. Daí que sua imagem costuma ocupar inteiramente a mente do vulgo, pois dificilmente podem imaginar alguma outra espécie de alegria que não seja a quem vem acompanhada da ideia de dinheiro como sua causa". (2008, p.359)
}

Filosofia e Educação - ISSN 1984-9605 - Volume 5, Número 1

Abril - Setembro de 2013 
emancipação dos trabalhadores, encaminhando-se para nova configuração da propriedade dos meios de produção, como propriedade verdadeiramente humana e social (idem, p.88). A palavra "social” dispõe-se aí em um contraste com outro "social": aquele que aparece como tal, mas é pura violência, servidão: o social do trabalho estranhado. Em sua nefasta unilateralidade, esse trabalho contribui para a rotura do tecido das relações sociais do trabalhador e os plenos poderes do capitalista.

Poucos anos depois, explode também a indignação de Marx e Engels contra a existência da família somente para a burguesia, enquanto que o proletariado era forçado a transformar suas crianças em meros artigos de comércio/instrumentos de trabalho, dispondo mulheres e filhas à prostituição pública (2003, p.42-43), e se expondo à escaldante concorrência com seus iguais. $\mathrm{O}$ ato de intercâmbio com a natureza e os outros seres humanos que se destina, inicialmente, à satisfação das necessidades de origem animal (como beber, comer e procriar) - as quais adquirem atributos humano-genéricos - tem seu duplo aspecto de apropriação e objetivação dilacerados pela propriedade privada. Ora, se o trabalho não se exteriorizasse, não se objetivasse, adquirindo existência material efetiva, não poderia ser apropriado pelo capitalista - e se o capitalista não possuísse as forças produtivas, não poderia forçar o trabalhador a entregar-lhe os processos de trabalho e os produtos dele resultantes. Conquanto bastante diversificado no seu impacto sobre os seres humanos (tal qual indica a profusão de estudos nas ciências humanas e da saúde), o trabalho estranhado não é um fenômeno típico do século XIX: é espinha dorsal do capitalismo.

\section{III}

Em sociedades estruturalmente desiguais, é razoável a um espinosano observar que corpo e mente padecem juntos e por igual ${ }^{10}$. Passiva com

${ }^{10}$ Das reflexões espinosanas, parece-nos destaque importante observar que o padecimento não toca apenas aos trabalhadores, mas também aos capitalistas, conquanto com profundas diferenças. Entretanto, evitando desvios quanto ao tema desse ensaio, ater-nos-emos a

Filosofia e Educação - ISSN 1984-9605 - Volume 5, Número 1

Abril - Setembro de 2013 
relação ao corpo (o qual, por sua vez, é passivo como objeto das relações de produção); concatenando os confusos fragmentos originários dos sentidos, a mente padece, como ideia do corpo que mais sofre a ação de causas externas do que causa suas próprias ações.

Por vezes, desumanizados até na satisfação de necessidades corporais básicas, os trabalhadores da educação têm seus seres atravessados pela servidão das paixões. No trabalho estranhado desfaz-se dramaticamente a relação entre labour e work: entre o trabalho em sua dimensão cotidiana, operativa, e humano-genérica, dotado de conteúdo emancipatório e significação social (para lembrar Duarte, 2001). Os corpos de professores em escolas públicas da infância ${ }^{11}$ são corpos que sacolejam em horas de transporte coletivo, na constante mobilidade da vida cotidiana. Corpos, em sua maioria, femininos - de mulheres exauridas por duplas jornadas, baixos salários, baixa escolarização, entre outros sinais da opressão de gênero ${ }^{12}$. Corpos suscetíveis às constantes afecções de outros corpos (inclusive de um corpo maior, a instituição) para execução de ideias e ações planejadas por tecnocratas que não se adequam à sua natureza, enfocando-os como abstrações sem potência de pensar, meros devedores de submissão ao discurso de seus comandantes. Corpos convivendo com instalações nada ergonômicas, em contato com velhas cadeiras e prédios em ruínas, que os afetam pelos cinco sentidos lembrando, como mostra Patto (2010), sua menoridade e invisibilidade social. Corpos e mentes sistematicamente ignorados, em sua essência, por quem desenha as políticas educacionais no Brasil: na sua maioria, economistas do sexo masculino, sem qualquer conhecimento teórico ou prático sobre educação - cuja indicação para os

caracterizar a relação entre trabalhador e trabalho estranhado.

${ }^{11}$ Grosso modo, admitiremos a noção de criança como pessoa que compreendida entre zero e doze anos de idade (conforme o Estatuto da Criança e do Adolescente, Brasil, s/d), e a infância, época da vida que lhe corresponde. Entretanto, nossa legislação educacional categoriza como "educação infantill" a etapa da educação básica entre zero e seis anos de vida, sendo os seis anos restantes parte do ensino fundamental.

${ }^{12}$ Para composição dessas reflexões sobre a vida diária dos professores da educação básica, utilizamo-nos do estudo de Gatti e Barreto (2009).

Filosofia e Educação - ISSN 1984-9605 - Volume 5, Número 1

Abril - Setembro de 2013 
principais postos da área aparece como aviso aos educadores sobre a impotência de seus corpos no agir, e de suas mentes, no pensar.

Os encontros habituais desses corpos se dão com crianças que, estigmatizadas pela pobreza, recebem a pecha de menores, a receber, do berço ao túmulo, especial atenção dos aparatos repressivos do Estado. Corpos que, por seu aspecto pauperizado (se comparados ao modelo de perfeição infantil difundido pelas grandes mídias) são causa de desagrado para os sentidos e má disposição do corpo ${ }^{13}$. Nesses encontros cuja história é dilacerada pela precarização da formação profisssional e da própria esfera pública $^{14}$, os professores atribuem muitos dos problemas emergentes na relação pedagógica aos seres dotados de relações de contiguidade e semelhança para com as crianças - as suas famílias (baseado em Patto, 2010). Flutuando ao sabor da opinião, podem, também, atribuir as causas de suas paixões aos entes considerados necessariamente livres, elaborando ideias confusas sobre suas próprias ações e os efeitos dessas ações, além das alheias. Em seu persistente desconhecimento sobre a essência dos indivíduos que compõem seu meio social, a vida em comum no modo de produção capitalista torna cada um contrário a todos os outros, não obstante a vital importância da escola no desenvolvimento de sujeitos mais capazes de fazer e pensar com o recurso à mediação social. Essas ideias ordenadas e concatenadas a partir dos sentidos são a ideia do corpo enquanto afetado por outros corpos, sendo confusas, e não adequadas. Em estado de servidão, a mente opera sobre as ideias das afecções tomando efeitos por causas, de acordo com a oportunista tutela dos mais diversos agentes sociais (estatais e

\footnotetext{
13 "Se, por exemplo, o movimento que os nervos recebem dos objetos que causaram tal movimento são chamados de belos, sendo chamados de feios aqueles que provocam o movimento contrário. Aqueles que provocam o sentido por meio do nariz são chamados de perfumados ou, então, de amargos insípidos; por meio do tato, de duros e ásperos ou, então, de moles e macios. E, finalmente, daqueles que provocam os ouvidos diz-se que eles produzem barulho ou, então, som ou harmonia [...] Tudo isso mostra suficientemente que cada um julga as coisas de acordo com a disposição de seu cérebro, ou melhor, toma as afecções de sua imaginação pelas próprias coisas.” (p.73)

${ }^{14}$ Este dado apresenta-se em um amplo estudo de Campos, Füllgraf \& Wiggers (2006) sobre o estado da arte das produções sobre educação infantil.
}

Filosofia e Educação - ISSN 1984-9605 - Volume 5, Número 1

Abril - Setembro de 2013 
não-estatais) ${ }^{15}$. Conforme afirma Chaui: “Ao suicídio individual corresponde, no plano intersubjetivo, a luta mortal das consciências e, no plano político, a guerra civil como luta entre facções" (2011, p.91).

A natureza relacional das atividades docentes e o seu dilaceramento revelam-se no elevado índice de transtornos psiquiátricos entre os professores, embora haja grandes variações nas estatísticas apresentadas por pesquisas no Brasil e no mundo ${ }^{16}$. Assunção e Oliveira (2009), a partir de Gatti et al., apontam que

o docente está envolvido em uma teia de relações com outras pessoas, alunos, colegas, funcionários, pais. Os resultados apresentados pelas autoras permitem afirmar que as boas relações no trabalho escolar são o principal fator de satisfação dentro do magistério. (p.358).

São elevados os níveis de estresse entre docentes de muitos países (Silva, 2006), chegando a altas taxas da chamada Síndrome de Burnout ${ }^{17}$. A mesma autora afirma como causa para essa síndrome a falta de participação nas decisões sobre os processos laborais.

\footnotetext{
${ }^{15}$ Nesse conceito, incluímos tanto instâncias educacionais estatais como também as empresas de produtos educacionais, e, mais recentemente, a indústria farmacêutica - em suas pesadas investidas no campo da chamada "medicalização da educação" (CRP/SP e Grupo Interinstitucional Queixa Escolar, 2010).

${ }^{16} \mathrm{O}$ uso de diferentes metodologias de pesquisa torna difícil a comparação da morbidade relacionada ao trabalho, mas podemos citar a identificação de altas taxas de transtornos psiquiátricos entre docentes de Belo Horizonte, Florianópolis, Vitória da Conquista, Bahia e São Paulo (Assunção e Oliveira, 2009; Silva, 2007). Entretanto, faltam estudos mais completos sobre a Síndrome de Burnout entre professores da educação infantil propriamente dita.

17 "Burnout é termo utilizado por autores estrangeiros para designar o estresse associado ao trabalho e foi traduzido para a língua portuguesa como "perder o fogo", "perder a energia". Segundo Malagris (2004), representa desgaste e falta de produtividade, caracterizado por um aspecto relacional, na medida em que é uma resposta ao estresse laboral crônico e não o estresse em si. O conceito original, embora tenha se desenvolvido na década de 1970, surgiu em 1969, como fenômeno psicológico que atinge trabalhadores assistenciais" (Silva, 2006, p.92). Caracterizada por uma acentuada perda de energia determinada pelo trabalho, a Síndrome pode apresentar-se como exaustão emocional, despersonalização, redução da satisfação em diversas esferas da vida, acompanhadas por irritabilidade e insensibilidade na relação com colegas e clientes, bem como a crença de que sua situação do trabalho não pode ser modificada.
}

Filosofia e Educação - ISSN 1984-9605 - Volume 5, Número 1

Abril - Setembro de 2013 
Como executor de trabalho estranhado, o docente está sob a permanente suspeita de vadiagem, dependente de motivos extrínsecos aos seus resultados como atividade humana, pois não é livre, e sim forçado; não tem se realizado com alegria e desejo, mas sim pela imposição do medo e por meio da desvalorização profissional - nesse estado, podem desconhecer a potência do seu próprio trabalho na educação da infância. A violência apresenta-se como intrínseca à sua realização. Não obstante, muitas concepções e políticas educacionais vêm professando um discurso voluntarista, com raízes religiosas, no qual prescrevem-se os afetos potentes como saída para as mais complexas mazelas educacionais, fazendo-se vistas grossas às causas dos bons encontros que os produzem.

Para essa cantilena aí está Gabriel Chalita, combinação de pseudointelectual, mercador de ideias velhas e um dos tecnocratas do sucateamento da educação pública em São Paulo. Em sua Pedagogia do afeto (2001), Chalita esquiva-se de qualquer conhecimento sociológico das condições de trabalho dos educadores, carimbando ad nauseam: "amem seus alunos! Tenham-lhes afeto!". A força desse apelo, somada à inserção de "obras" do autor entre referências obrigatórias para muitos concursos públicos de ingresso na docência (termômetro de sua convergência com as atuais políticas), traduziu-se em estrondoso sucesso de vendas: o autor declara o score de dez milhões de livros vendidos (Kachani, 2010).

Entretanto, Chalita é apenas um ponto na reta da história da educação de nossas crianças, eivada pela defesa do trabalho "por amor" ou "voluntário" do educador. Nela se oculta sua desvalorização social, sua condição de trabalho forçado, sacrificado. Fundado em um assistencialismo impregnado de cristianismo, esse discurso perdura por mais de um século na educação pública (tanto nas políticas quanto concepções pedagógicas), especialmente a infantil. Citem-se as instituições pré-escolares assistencialistas difundidas entre 1899 e $1922^{18}$; o Plano de Assistência ao

${ }^{18}$ Kuhlmann Jr (2010) considera importante o período entre 1899 e 1922 para implantação das primeiras propostas de instituições pré-escolares no Brasil, em uma conjuntura

Filosofia e Educação - ISSN 1984-9605 - Volume 5, Número 1

Abril - Setembro de 2013 
Pré-Escolar com financiamento público de espaços educacionais para igrejas de diferentes denominações, livres para escolher seu quadro de pessoal entre os fiéis ${ }^{19}$; a expansão nacional da educação pré-escolar capitaneada pelo Movimento Brasileiro de Alfabetização (MOBRAL) nos anos 1980, conforme Arce (2008); a cultura do auto-sacrifício docente na Revista "Nova Escola", defensora do papel do professor como ouvinte de descontentamentos, medos e esperanças dos alunos - fórmula mágica para resolução de problemas disciplinares, falta de motivação e insatisfação com a escola (Faria, 2002, p.153). Tal voluntarismo lembra a célebre reflexão de Marx:

A religião é o suspiro do ser oprimido, o íntimo de um mundo sem coração e a alma de situações sem alma. É o ópio do povo. A miséria religiosa constitui ao mesmo tempo a expressão da miséria real e o protesto contra a miséria real. O banimento da religião como felicidade ilusória dos homens é a exigência da sua felicidade real. $\mathrm{O}$ apelo para que abandonem as ilusões a respeito da sua condição é o apelo para abandonarem uma condição que precisa de ilusões. (2004, p.45-46)

Segundo Chaui (2011, p.90) a servidão pode ser compreendida como aumento imaginário da força para existir, acompanhada pela diminuição real da mesma força. Per se, a mente não se equivoca ao imaginar. Pelo contrário! A imaginação seria força da mente se esta soubesse que imagina (idem, p.82). Sob uma perspectiva espinosana, as injunções religiosas - e voluntaristas, de modo geral - são úteis como meios imaginários de lidar com a impotência percebida, mas inócuos na resolução de problemas reais.

internacional pautada pelo médico-higienismo, a eugenia e a vigilância contra a criminalidade nas classes populares.

19 Sob os auspícios do UNICEF, esse plano difundiu-se, em 1967, por meio do Departamento Nacional da Criança (DNCr) (Kuhlmann Jr, 2003). "Nem se pensa na formação profissional: o pessoal seria recrutado entre 'pessoas de boa vontade', à base de voluntariado, reservando-se o pagamento para alguns técnicos necessários à supervisão e coordenação dos serviços, cujos encargos seriam de maior responsabilidade." (idem, p.489)

Filosofia e Educação - ISSN 1984-9605 - Volume 5, Número 1

Abril - Setembro de 2013 
O discurso de Chalita e outros autores da auto-ajuda educacional pode ser relacionado ao momento de crise do modo de produção capitalista, no qual Mészáros (2008) observa a difusão do apelo retórico à consciência individual como reação à suposta "crise de valores" subjacente ao aumento da criminalidade. Esse discurso destina-se ao fracasso porque não altera as causas reais desses fenômenos sociais, cujo malogro cede espaço ao inatismo da antropologia criminal do século XIX, repaginado pela poderosa tecnologia do XXI: "as personificações políticas do alto escalão do capital, inclusive o mais alto deles, começam a falar de como podem identificar a futura delinquência já "no útero da mãe" (idem, p.93). Particularmente nas políticas para a população mais pobre, ou se apresenta o social como internalização do finalismo moralista (a despeito do pragmático fetichismo imanente ao modo de produção capitalista), ou se propõe a negação do direito de crianças e adolescentes a qualquer forma de socialização mediada pelo Estado, reduzindo tantos deles à condição de seres biologicamente perigosos para a sociedade humana - e, em um ou outro caso, como afirma Mészáros, apresenta-se ao indivíduo uma sociedade estruturalmente imutável e impermeável à ação individual e/ou coletiva. Em outras palavras: sociedade orquestrada pela tentativa de generalizar a impotência, cuja participação da ampla maioria dos seres humanos encolheu-se dramaticamente.

\section{IV}

Podemos, agora, ensaiar breve resposta à questão que intitula este texto. Nossa epígrafe apresenta, com meridiana clareza, a negativa de Espinosa à possibilidade de domínio absoluto dos afetos - obviamente, isso se aplica também ao trabalho docente. O homem não é império dentro de um império, sendo falso acreditar que seus afetos possam ser determinados apenas por ele próprio. Essa ideia espinosana deita por terra a crença capitalista de que a mente domina o corpo e o homem pode introduzir seu Verbo livre em uma

Filosofia e Educação - ISSN 1984-9605 - Volume 5, Número 1

Abril - Setembro de 2013 
natureza submissa. Destrói também a oca estrutura do discurso em defesa da "boa vontade" do trabalhador, pois a vontade é apenas o apetite, enquanto se refere à mente. Seria, pois, impossível haver alegria e desejo a partir das formas de trabalho estranhado em que persevera radical impotência; nas quais a essência atual dos indivíduos não se expressa em bons encontros e liberdade da razão. O processo de transformar as paixões em ações, criando laços sociais caracterizados pela alegria e desejo de conhecimento e convivência, mudando o cego conatus em desejos racionais, coincide com o desenvolvimento da potência de agir e pensar dos educadores e das crianças, em sua essência atual necessariamente complexa. Não se cria à margem da consideração de que educar é promover liberdade da Razão, nem a constituição de uma estrutura jurídico-política com ela condizente - pois é útil o que conduz à sociedade comum dos homens (Espinosa, 2008, p.293).

Espinosa é fundamental no reconhecimento da indissociável unidade mente-corpo no processo de trabalho e debate sobre os objetivos específicos do trabalho pedagógico, para além do finalismo moralista tão presente em diversas concepções e políticas que, há mais de um século, abordam a educação da infância brasileira. Como trabalho estranhado, fonte de sofrimento, desenvolvido em relativo isolamento social - a despeito de seu próprio produto ser social: a formação de novas personalidades - para Mészáros (2008, p.65), só pode transformar-se por meio de mudanças estruturais do modo de produção capitalista. $\mathrm{O}$ autor defende a necessidade de mudança qualitativa das condições objetivas de reprodução sociometabólica do modo de produção, acompanhada pela transformação progressiva da consciência em resposta à transição das referidas condições. O papel da educação na elaboração de estratégias apropriadas para esses dois eixos é soberano.

O autor sustenta que, sem duas formas de universalização interdependentes - a universalização da educação e a do trabalho como atividade humana autorrealizadora - nenhuma mudança estrutural será 
capaz de romper com iniciativas superficiais e reformistas. Crítico do "apelo à consciência" de talhe voluntarista, Mészáros advoga em favor da força social real do ethos socialista integrado à situação social e histórica efetiva, sem a projeção de algum "ideal externo" a que os indivíduos devam se conformar, mas sim defendendo a articulação da ação de indivíduos sociais em um movimento de mudança progressiva e estrutural do controle sociometabólico do capital. Trans(formação) da consciência e articulação política são, assim, forças imanentes para mudanças essenciais, resultado da constituição de movimentos autogestionários no próprio processo de sua formação.

Sem pretensão de síntese, é mister observar que o pensamento revolucionário de Mészáros (bastante representativo dos fundamentos do pensamento marxiano) aproximam-se de algumas ideias espinosanas, distanciando-se de outras. Tal como o marxismo, o espinosismo não defende o "primado do individualismo" (mais semelhante ao estado de natureza que ao civil), como horizonte ético. Pelo contrário: o indivíduo pode crescer em potência apenas por meio da formação de laços sociais especialmente, aqueles firmados sobre a colaboração - diminuindo-se com o empreendimento solitário de sua jornada desejante. Aduzimos que a passagem do estado de natureza ao estado civil implica na construção de uma norma de vida comum ${ }^{20}$ a partir da multiplicação do conatus individual pelo coletivo: a colaboração de muitos cidadãos multiplica as forças individuais. E se, no estado civil, vivermos sob a condução da razão (conforme o segundo gênero de conhecimento, mas também a razão vivenciada como um afeto) e seus afetos (que são desejos: piedade, lealdade), os outros homens ser-nos-ão ainda mais úteis. Se não é possível à mente imperar sobre o corpo, ou à "vontade" vencer a "paixão", é perfeitamente concebível regular os afetos sob a condução da razão. Entre outros aspectos, porque o monismo espinosano rompe com o dualismo

$\overline{{ }^{20} \text { Em Espinosa (2004a }}$, p.370) temos "regra comum de vida". 
cartesiano ao reconhecer a ideia como estruturalmente pertencente à modalidade operativa do afeto - as ideias são parte do afeto, não se opondo a ele (Fernández G., 1999, p.89-108). Como afirma Espinosa (p.273): o afeto pode se desvincular do pensamento da causa exterior e se vincular a pensamentos verdadeiros.

Sob tais aspectos, educar o educador à moda espinosana não se dissocia de promover sua potência real por meio da pertença a coletivos políticos - pois a utilidade mútua dos homens aumenta na proporção mesma da semelhança de suas essências atuais ${ }^{21}$. Espinosa, ao considerar como mutável a essência humana (ver Espinosa, 2008, p.313), defende que o fortalecimento da natureza social a ela imanente é indispensável para o aumento da potência individual. Afetos potentes, como o "amor aos alunos" (sendo o amor entendido como alegria acompanhada da ideia de uma causa exterior), ao invés de ser causa dos problemas educacionais - questão de "boa vontade" ou domínio da mente sobre o corpo - são expressão da natureza multicausal desses mesmos processos, em concordância com a essência atual dos sujeitos neles implicados. Nesse sentido, a superação do trabalho estranhado demanda a ampla mudança das condições nas quais se realiza e de seu papel na "essência atual" dos educadores, talhada em uma história de padecimento, superstição, servidão. No que toca ao processo de formação de professores, ao invés da habitual crítica aos seus déficits

\footnotetext{
${ }^{21}$ Note-se que "comum" não é mero sinônimo de "semelhante" em Espinosa (2008). "Espinosa entende por noções comuns a propriedades comuns e universais presentes nos seres singulares finitos de mesma natureza; as noções comuns, além de qualidades comuns ou universais entre os semelhantes, são também as leis naturais ou a ordem e a conexão necessárias entre os seres da Natureza" (Chaui, 2001, p.339). Seres que se conduzem pela razão assemelham-se mais do que em uma condição de servidão, pois partilham uma propriedade infinita da natureza humana, enquanto que, neste último caso, buscam bens finitos, rivalizando e obstaculizando-se mutuamente. A esse respeito, ver o artigo de Cristiano Novaes de Rezende publicado neste Dossiê. As partes III, IV e V da Ética, o Tratado Político e o Tratado Teológico-Político, bem como bibliotecas de comentários, exploram o percurso para uma medicina mentis (bom exemplo é o mesmo artigo de Rezende) no nível individual e para a superação do sistema medo-esperança no nível coletivo (ver Chaui, 2011, p.170).
}

Filosofia e Educação - ISSN 1984-9605 - Volume 5, Número 1

Abril - Setembro de 2013 
(segundo Patto, 2010), faz-se necessário conhecê-los em sua complexidade, gerando condições para expressão e produção de sua potência criadora.

A despeito de reconhecermos essa proximidade entre espinosismo e marxismo no que se refere ao reconhecimento da importância da natureza social dos homens como foco indispensável da mudanças sociais, não podemos afirmar com segurança que Espinosa tenha constituído um pensamento sobre possíveis mudanças estruturais da sociedade. Nesse ponto, a crítica espinosana difere do marxismo ortodoxo, embora haja quem considere inexato atribuir-lhe reformismo. Tratando das especificidades da causalidade eficiente imanente, afirma Chaui (1983, p.272) que, sendo imanente a causa instituinte de uma forma política, suas instituições e acontecimentos a exprimem de modo determinado. Portanto, um regime político tirânico é assim instituído, ainda que a princípio os seus efeitos não sejam visíveis. A partir desse aspecto se constitui a crítica ao reformismo político, uma vez que não basta agir sobre os efeitos para modificar a natureza da forma política e social, sendo necessário, para mudá-la, destruir sua causa originária.

Tendo precedido o capitalismo industrial e os economistas políticos modernos, ao invés de, como Marx, projetar uma alternativa revolucionária ao modo de produção capitalista - o comunismo - Espinosa defende a democracia no seu inacabado Tratado Político, texto interrompido justamente no capítulo que sobre ela versa. Certo de que a experiência já mostrara todos os tipos de cidade que se podiam conceber, Espinosa assenta suas reflexões sobre o Estado na busca da paz e da segurança coletivas ${ }^{22}$. Entretanto, "paz" não é sinônimo de "silêncio" - pois, se assim for, ela leva o estigma da servidão, barbárie e solidão, sendo lamentável para o homem:

\footnotetext{
${ }^{22}$ No Capítulo II do Tratado Político, §17: "Há o costume de chamar poder público a este direito que define o poder do número, e possui absolutamente este poder quem, pela vontade geral, cuida da coisa pública, isto é, tem a tarefa de estabelecer, interpretar e revogar as leis, defender as cidades, decidir da guerra e da paz etc. Se esta tarefa compete a uma assembléia composta por todos os cidadãos, o poder público é chamado democracia". (p.446)
}

Filosofia e Educação - ISSN 1984-9605 - Volume 5, Número 1

Abril - Setembro de 2013 
Cap 5: § - 4. [...] A paz, com efeito, não é a simples ausência de guerra, é uma virtude que tem a sua origem na força da alma, pois que a obediência [...] é uma vontade constante de fazer o que, segundo o direito comum da cidade, deve ser feito. Uma cidade, é preciso dizê-lo ainda, em que a paz é efeito da inércia dos súditos conduzidos como um rebanho e formados unicamente na servidão, merece mais o nome de solidão que o de cidade. (Espinosa, 2004b, p.459)

\section{Referências bibliográficas}

ARCE, Alessandra. O MOBRAL e a educação de crianças menores de seis anos durante o regime militar: em defesa do trabalho voluntário. Cadernos CEDES, Campinas, v. 28, n. 76, p.379-403, Dez. 2008.

ASSUNÇÃO, Ada Ávila; OLIVEIRA, Dalila Andrade. Intensificação do trabalho e saúde dos professores. Educaşão e Sociedade, Campinas, v. 30, n. 107, Aug. 2009.

BRASIL. Estatuto da Criança e do Adolescente. Lei no 8069 de 13 de julho de 1990. Brasília: Presidência da República, Casa Civil, (s/d). Disponível em: http://www.planalto.gov.br/ccivil 03/Leis/L8069.htm.

CAMPOS, Maria Malta; FÜLLGRAF, Jodete; WIGGERS, Verena. A qualidade da educação infantil brasileira: alguns resultados de pesquisa. Cadernos de Pesquisa, vol.36, n.127, p.87-128, jan/abr. 2006.

CHALITA, Gabriel. Educação: a solução está no afeto. São Paulo: Gente, 2001, 263 p.

CHAUI, Marilena. Marx e a democracia (o jovem Marx leitor de Espinosa). In: FIGUEIREDO, Eurico de Lima; CERQUEIRA FILHO, Gisálio; KONDER, Leandro. Por que Marx? Rio de Janeiro: Graal, 1983, p.257-292.

CHAUI, Marilena. Espinosa: uma filosofia da liberdade. 2a ed. São Paulo: Moderna, 2005, 104 p.

CHAUI, Marilena. Desejo, paixão e ação na ética de Espinosa. São Paulo: Companhia das Letras, 2011, 356 p.

Filosofia e Educação - ISSN 1984-9605 - Volume 5, Número 1

Abril - Setembro de 2013 
CONSELHO REGIONAL DE PSICOLOGIA DE SÃO PAULO [CRP/SP]; GRUPO INTERINSTITUCIONAL QUEIXA ESCOLAR. Medicalização de crianças e adolescentes: conflitos silenciados pela redução de questões sociais a doenças de indivíduos. São Paulo: Casa do Psicólogo, 2010, 290 p.

DEBORIN, Abram Moiseevich. Spinoza's world-view. In: KLINE, George (Ed.). Spinoza in soviet philosophy. London: Routledge and Kegan Paul, 1952, p. 90-119.

DUARTE, Newton. Educação escolar, teoria do cotidiano e a escola de Vigotski. 3. ed. Campinas, SP: Autores Associados, 2001, 115 p.

ENGELMANN, Arno. (1978) Os estados subjetivos: uma tentativa de classificação de seus relatos verbais. São Paulo: Ática.

ESPINOSA, Bento de. Ética. 2a ed. São Paulo: Autêntica, 2008. (Trabalho original publicado em 1677).

ESPINOSA, Baruch. Ética. In Espinosa. São Paulo: Nova Cultural, 2004a. (Os

Pensadores) p.141-404.

ESPINOSA, Baruch. Tratado Político. In Espinosa. São Paulo: Nova Cultural, 2004b. (Os Pensadores) p.437-516.

FARIA, Gina Glaydes Guimarães de. Nova Escola: um projeto político-pedagógico em andamento (1986-2000). 2002. 210 p. Dissertação (Mestrado em Educação Brasileira) - (Faculdade de Educação, Universidade Federal de Goiás). Goiânia.

FERNÁNDEZ G., E. (1999) Dominio de los afectos. In: J. BLANCOECHAURI (Ed.). Espinosa: Ética e Politica (p.73-112). Encontro HispanoPortugués de Filosofia, Santiago de Compostela: Universidade, Servicio de Publicacións e Intercambio Científico, 5-7 de Abril de 1997.

KACHANI, Morris. Gabriel Chalita diz já ter vendido mais de dez milhões de livros. Folha de S. Paulo, 07/05/2011. Ilustrada. http:// folha.com/il912381 GATTI, Bernadete Angelina; BARRETO, Elba Siqueira de Sá (Coord.) Professores do Brasil: impasses e desafios. Brasília: UNESCO, 2009, 294 p. 
GIANNOTTI, J. A. (1999) Marx: vida e obra. In K. Marx. Para a crítica da economia política; Do Capital; O Rendimento e suas Fontes. São Paulo, Nova Cultural.

GOULD, S. J. A falsa medida do homem. 2. ed. Tradução Valter Lellis Siqueira. São Paulo: Martins Fontes, 1999. 369 p.

HULL, G. Marx's anomalous reading of Spinoza. Interpretation, vol. 28, n.1, Fall 2000, p.17-31.

KUHLMANN JÚNIOR, Moysés. Educando a infância brasileira. In: LOPES, Eliane Marta de Teixeira; FARIA FILHO, Luciano Mendes de; VEIGA, Cynthia Greive (Orgs). 500 anos de educação no Brasil. 3a ed. Belo Horizonte, Autêntica, 2003, 608 p.

KUHLMANN JÚNIOR, Moysés. Infância e Educação infantil: uma abordagem histórica. 5 ed. Porto Alegre, RS: Mediação, 2010, 191 p.

LUKÁCS, György. O jovem Marx. Sua evolução filosófica de 1840 a 1844. In: O jovem Marx e outros escritos de filosofia. 2 ed. Rio de Janeiro: Editora UFRJ, 2009, p.121-202. (Trabalho originalmente publicado em 1955)

MARX, K. Manuscritos econômico-filosóficos. São Paulo: Boitempo, 2010, 191 p. (Textos originais de 1844)

MARX. Contribuição à crítica da Filosofia do Direito de Hegel. In Manuscritos Econômico-filosóficos.São Paulo: Martin Claret, 2004, p.45-63. (Trabalho original publicado em 1844)

MARX, Karl; ENGELS, Friedrich. Manifesto Comunista. São Paulo: Instituto José Luís e Rosa Sunderman, 2003, 68 p. (Trabalho original publicado em 1848)

MÉSZÁROS, István. A educação para além do capital. 2 ed. São Paulo: Boitempo, 2008. 126 p.

PATTO, Maria Helena de Souza. 3 ed. A Produção do Fracasso escolar: histórias de submissão e rebeldia. São Paulo: Casa do Psicólogo, 2010. 464 p.

RANIERI, Jesus. Apresentação - sobre os chamados Manuscritos EconômicoFilosóficos de Karl Marx. In: MARX, K. Manuscritos econômico-filosóficos. São Paulo: Boitempo, 2010, p.11-17. 
SILVA, Flávia Gonçalves da. O professor e a educação: entre o praz̧er, o sofrimento e o adoecimento. 2007. Doutorado em Educação (Psicologia da Educação)

SILVA, Maria Emília Pereira da. Burnout: por que sofrem os professores? Estudos e Pesquisas em Psicologia, v. 6, n.1, p. 89-98, 2006.

VYGOTSKI, Lev Semionovich. Teoria de las emociones: estudio histórico-psicológico. Madrid: Akal, 2004, 260 p. (Texto original de 1933). 